Toxicology Mechanisms and Methods

November 2006 ; Volume 16 (8) : Pages 431-437

http://dx.doi.org/10.1080/15376520600698717

(c) 2006 Taylor \& Francis, Informa
Archimer http://www.ifremer.fr/docelec/ Archive Institutionnelle de l'Ifremer

The original publication is available at http://www.tandf.co.uk/journals/

\title{
In Vitro Test-Based Comparison of Pesticide-Induced Sensitivity in Marine and Freshwater Phytoplankton
}

\author{
Geneviève Arzul ${ }^{a,{ }^{*}}$, Françoise Quiniou ${ }^{a}$ and Cécile Carrie ${ }^{b}$ \\ a Ifremer, Department of Biogeochemistry and Ecotoxicology, 29280 Plouzané, France \\ ${ }^{\text {b }}$ Pôle Analytique des Eaux, , 29280 Plouzané, France \\ *: Corresponding author : G. Arzul, Phone : 332982243 26, Fax : 332982245 94, email address : \\ genevieve.arzul@ifremer.fr
}

\begin{abstract}
:
This study aims to assess the effects of two pesticides, namely the insecticide carbofuran and the herbicide isoproturon, on monospecifically cultivated marine and freshwater phytoplankton according to standard methods. In the presence of pesticide, growth rates were lower in marine species Chaetoceros gracilis and Phaeodactylum tricornutum than in freshwater species Chlorella vulgaris and Selenastrum capricornutum after 72 hours. The EC50 values were obtained with the REGTOX Macro software, and the NEC values by applying the DEBtox model.
\end{abstract}

Keywords: DEBtox model, Freshwater phytoplankton, Marine phytoplankton, Pesticides, REGTOX Macro

\section{Introduction}

The effect of xenobiotic substances on aquatic organisms is currently taken into account when carrying out quality assessments of the environment. However there is a lack of information available regarding adverse effects on marine and freshwater ecosystems as a result of contamination. A great deal of data about toxicant concentration thresholds is available as a way of conserving satisfactory freshwater conditionss; on the other hand, recent concerns have been expressed about the risks incurred by the marine environment (Oudin and Maupas, 1999; Oganisation for Economic Cooperation and Development (OECD), 1994). Current awareness of its fragility together with the total lack of data regarding the responses of the marine ecosystem when subjected to land pollution have justified the provisional shift of standard freshwater toxicity tests and models to the marine and estuarine areas. However, a direct application of these methods is questionable. Firstly, the biodiversity in coastal marine and estuarine ecosystems is extensive, and physiological sensitivity adapts to fluctuating physico-chemical conditions (Petersen and Gustavson, 2000). Secondly, in the case of persistent and bioaccumulative substances, there is a risk of long-term toxicity as regards the top consumers, and thus the acceptance of concentrations considered as relatively low may be of great concern (His and Seaman,1993).

The laboratory investigations reported here were conducted to compare the effects induced by two biocides, carbofuran and isoproturon, on phytoplankton growth; the former is used in soil and seed 
protection, whereas the latter, a phenylurea herbicide, is a weed-killer and is used on cereal crops. For this study, phytoplankton was collected from freshwater and seawater and cultivated under standard conditions (AFNOR, 1993; AFNOR, 1998). Two ecotoxicity standards were considered: NOEC (No Observed Effect Concentration, i.e. the concentration below which no adverse effects are observed), and EC50 (Effective Concentration of the pesticide that reduces either biomass, or growth rate by $50 \%)$. Finally, in order to relate our results to natural situations, particular attention was focussed on the algal biomass and growth rate of freshwater and marine algae species subjected to herbicide doses close to their respective EC50 concentrations, which were added at different developmental stages. 


\section{MATERIAL AND METHODS}

\section{Pesticides}

Both pesticides were purchased from Sigma-Aldrich (38297

St Quentin-France). Isoproturon (3- (4-Isopropylphenyl)- 1, 1-dimethylurea) is a selective systemic herbicide that controls the development of weeds by affecting the photochemical 80 activity of Photosystem II (El Jay et al. 1997; Robert 1998). Carbofuran (2, 3-Dihydro-2, 2-diméthylbenzofuran-7-yl methylcarbamate) is an insecticide that inhibits lipid metabolism and acetylcholinesterase activity (Robert and Hutson 1999). Each pesticide stock solution was directly prepared in one liter of either freshwater or artificial seawater by dissolving $400 \mathrm{mg}$ carbofuran or $100 \mathrm{mg}$ isoproturon, under a 60$\mathrm{h}$ magnetic stirring in darkness and room temperature. No organic solvant was used in order to avoid any uncontrolled effects. Then, saturated stock solutions were sterilized by

filtering through Stericap $(0.22 \mu \mathrm{m}$ porosity, Sterile Millipore Express Membrane for Pressure Filtration System, Millipore Corporation, Bedford, MA). The samples were stored frozen in previously burnt glass bottles until use, which was no more than
1 month. Then the effective pesticide concentration was checked in a subsample by chemical analysis. Chemical analyses were performed at the "Pole Analytique des Eaux" laboratory using the methods of Molina et al. (1995) for isoproturon and Durand et al. (1992) for carbofuran. Due to the strong dilutions needed for isoproturon, the samples were concentrated on a 47-mm solid phase- disk (ENVI ${ }^{\mathrm{TM}}-18 \mathrm{DSK}$, Solid Phase extraction disks, 100 Cat. $\mathrm{N}^{\circ}$ 57171, Supelco, Bellefonte, PA, USA), then eluated in methanol prior to analysis.

\section{Sensitivity of Different Phytoplankton Species to Pesticides}

The phytoplankton was selected following standard di- 105 rectives. For freshwater tests, two chlorophytes, Selenastrum capricornutum and Chlorella vulgaris, were provided by the Institut Pasteur de Lille (France) and cultivated in a medium defined according to the international ISO 8692 protocol (AFNOR 1993). Marine tests were performed on two di- 110 atoms, Phaeodactylum tricornutum (strain CCAP 1062/1A) and Chaetoceros gracilis (from SATMAR, Saint-Vaast-La-Hougue,

\section{A - Chlorella vulgaris growth rate}
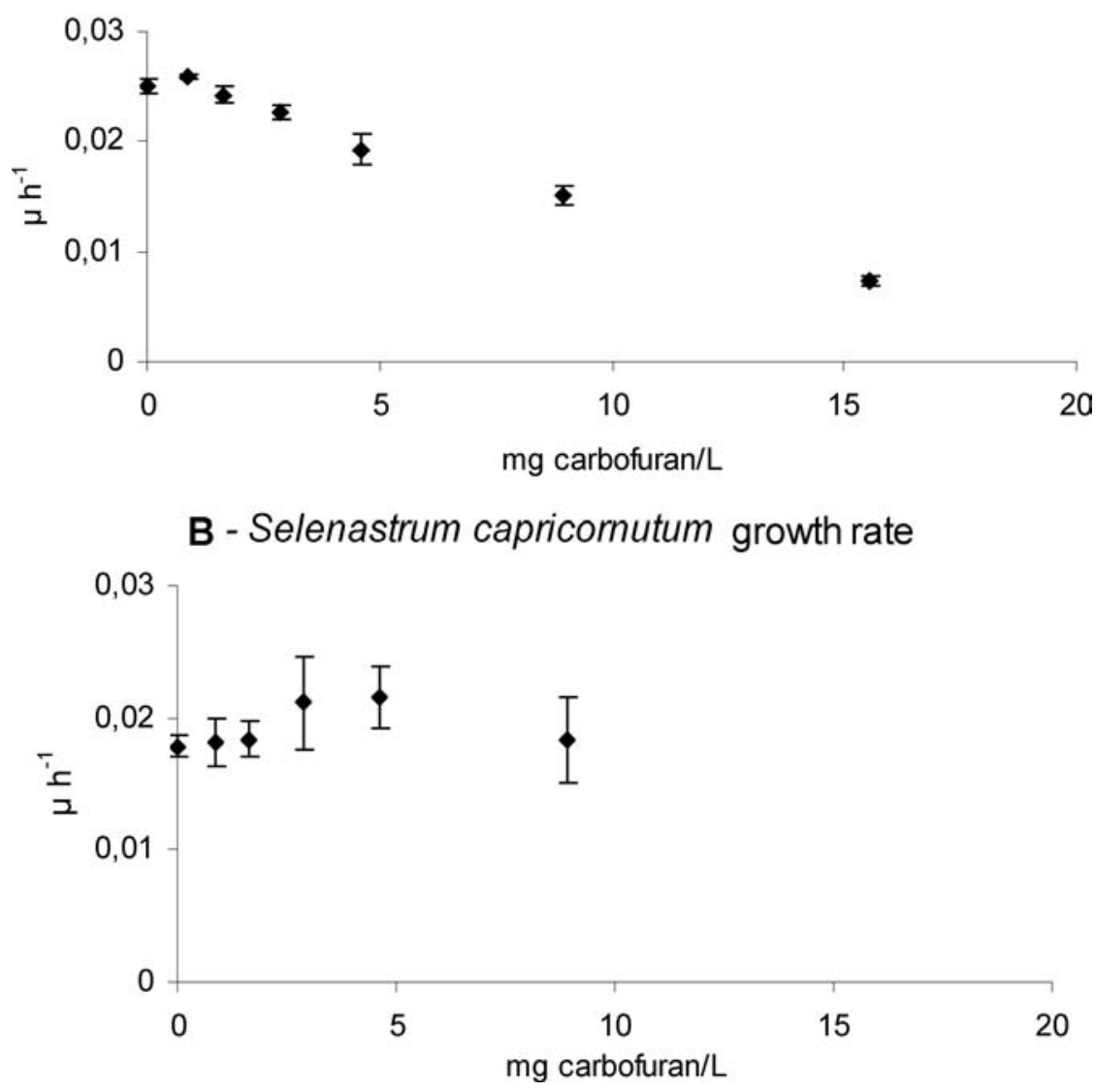

FIG. 1. Freshwater algae growth rate versus different doses of carbofuran. A: C. vulgaris; B: S. capricornutum. $\mathrm{N}=3$, bars: standard deviation at the $95 \%$ confidence level. 
France) cultivated in artificial seawater containing a medium defined in ISO 10253 (AFNOR 1998). Although C. gracilis was

115 not included in the standard species, it was selected to represent the common diatom population in coastal seawater (Varela et al. 2005). The algal stock cultures were maintained in exponential growth in precultures started 3 to 4 days before the beginning of the test (AFNOR 1993). The precultures were incubated under

120 the same conditions as those in the test below.The algal cells were inoculated $\left(0.2 \times 10^{4}\right.$ to $\left.10^{4} \mathrm{cell} / \mathrm{mL}\right)$ into the liquid culture media prepared with increasing concentrations of the pesticide as follows:

$* 0.88,1.64,2.86,4.62,8.94,15.56 \mathrm{mg} / \mathrm{L}$ for carbofuran and freshwater algae

$* 1.0,1.80,3.20,5.60,10.0,18.0 \mathrm{mg} / \mathrm{L}$ for carbofuran and marine algae

$* 1.19,5.93,13.03,25.09,50.19,88.99,475.08 \mu \mathrm{g} / \mathrm{L}$ for isoproturon and freshwater algae

$130 * 1.35,6.77,9.26,12.35,33.67,67.34,128.37 \mu \mathrm{g} / \mathrm{L}$ for isoproturon and marine algae.
Each treatment was assayed in triplicate. A triplicate pesticidefree control sample was also cultivated under the same conditions, and the effective pesticide concentrations were analyzed in the cultures at the beginning and the end of the bioassays. The 135 cultures were grown in borosilicated tubes (40-mL cultures), and incubated in a temperature-controlled chamber $(21 \pm$ $0.5^{\circ} \mathrm{C}$ ) under continuous photosynthetically active radiation (PAR, 90-95 $\mu \mathrm{mol}$ quanta $/ \mathrm{m}^{2} / \mathrm{s}$ ) measured with a spherical probe QSL 101 (Biospherical Instruments Inc. San Diego, CA, 140 USA).

Algal growth was monitored by the direct measurement of chlorophyll fluorescence with a Turner fluorometer (Turner Designs, Inc. Sunnyvale, CA 94085; excitation filter 430-450nm, emission 650-680nm). For a given pesticide concentration, the 145 cellular fluorescence intensity was directly proportional to the cell concentration estimated from microscopic cell counting in some samples. Measurements were performed daily for 3 days, following the standard procedures ISO 8692 (AFNOR 1993) and ISO 10253 (AFNOR 1998) for freshwater and marine 150 phytoplankton, respectively.

\section{A - Chaetoceros gracilis growth rate}

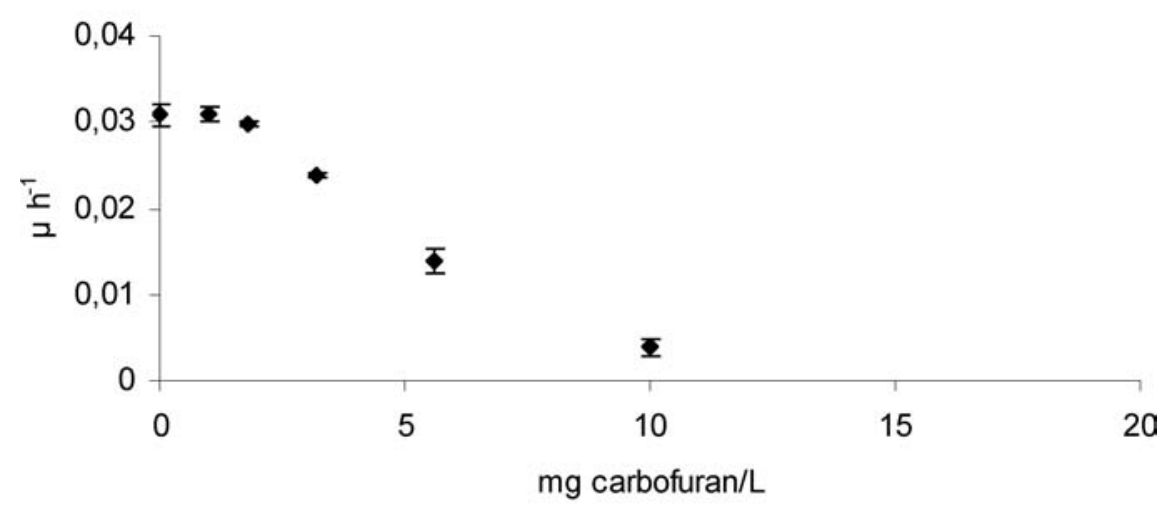

\section{B - Phaeodactylum tricornutum growth rate}

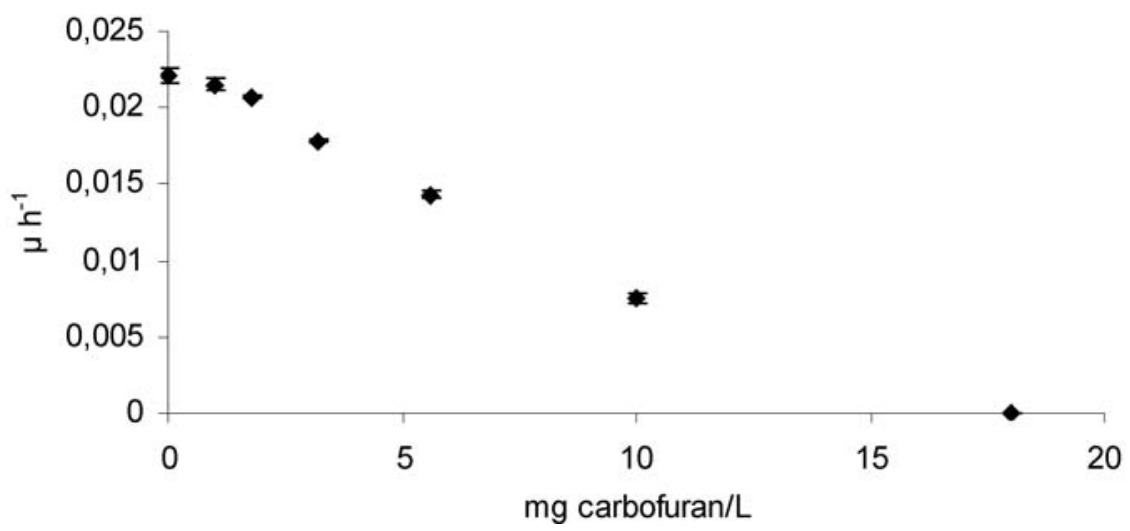

FIG. 2. Marine algae growth rate versus different doses of carbofuran. A: C. gracilis; B: P. tricornutum. $\mathrm{N}=3$, bars: standard deviation at the $95 \%$ confidence level. 


\section{Determination of Toxicity Endpoints}

For each microalgal species studied, AFNOR $(1993,1998)$ 155 recommendations were applied to evaluate the impact of the pesticide on the cell concentration.

The EC50 were calculated 72 hours after algae inoculation. For each culture, the growth rate was calculated after log transformation and the EC50 was obtained applying the Excel Macro REGTOX, according to Vindimian et al. (1983). In this case the REGTOX model was based on the equation of Hill (in Vindimian et al. 1983).

The NEC was estimated using the DEBtox model described by Kooijman et al. (1996). In the model, the cells grow exponentially and the pesticide has a linear effect on the growth

\section{RESULTS AND DISCUSSION}

\section{Effective Pesticide Concentrations}

In general, the solubility values measured in our saturated stock solutions of isoproturon and carbofuran were higher than

those reported in the literature for pure freshwater (Robert 1998; 170 Robert and Hutson 1999) (Table 1).

\section{Effect of Carbofuran}

In $C$. vulgaris, the growth was enhanced by the addition of $0.88 \mathrm{mg} / \mathrm{L}$ carbofuran (Fig. 1), cell density being statistically different from the control ( $\mathrm{p}<0.05$ ). In $S$. capricornutum, this 175 hormetic effect was particularly conspicuous (Stebbing 1982; Bérard and Pelte 1996); the addition of either 2.85 or $4.64 \mathrm{mg} / \mathrm{L}$ carbofuran caused relatively similar stimulations. But, the variability in the $S$. capricornutum results was substantial. Regarding carbofuran toxicity, our experimental data failed to 180 exhibit a significant toxic effect, probably due to the fact that the highest carbofuran concentration was only $8.94 \mathrm{mg} / \mathrm{L}$. In the case of $C$. vulgaris, the highest tested concentration, $15.56 \mathrm{mg} / \mathrm{L}$, was toxic and reduced growth rate by $70 \%$.

Concerning marine phytoplankton, $3.20 \mathrm{mg} / \mathrm{L}$ of carbofuran 185 significantly inhibited algal growth (Fig. 2). A higher dose, $10 \mathrm{mg} / \mathrm{L}$, produced $87 \%$ inhibition in C. gracilis, but only up

\section{A - Chlorella vulgaris growth rate}

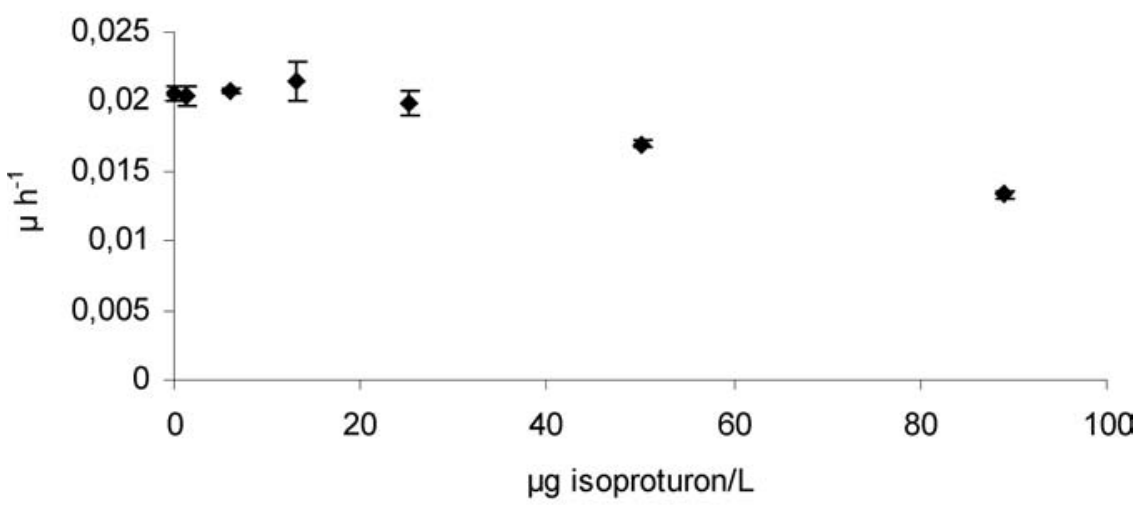

B - Selenastrum capricornutum growth rate

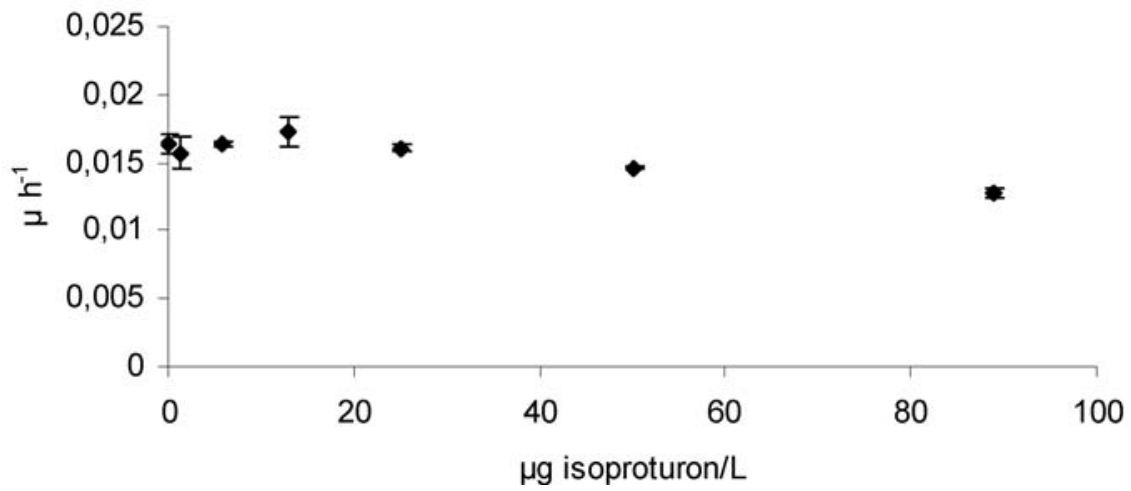

FIG. 3. Freshwater algae growth rate versus different doses of isoproturon. A: C. vulgaris; B: S. capricornutum. $\mathrm{N}=3$, bars: standard deviation for $95 \%$ confidence level. 
TABLE 1

Effective pesticide concentrations in the saturated stock solutions, and water solubility given by Robert 1998* and Robert and Hutson 1999**

\begin{tabular}{lccc}
\hline & $\begin{array}{c}\text { ISO 10253 } \\
\text {-marine } \\
\text { medium }\end{array}$ & $\begin{array}{c}\text { ISO 8692 } \\
\text {-freshwater } \\
\text { medium }\end{array}$ & $\begin{array}{c}\text { Water } \\
\text { solubility }\end{array}$ \\
\hline Isoproturon, mg/L & 348 & 396 & $320 *$ \\
Carbofuran, mg/L & 60 & 89 & $65 * *$ \\
\hline
\end{tabular}

to $70 \%$ in $P$. tricornutum. These experimental data highlight the higher sensivity of $C$. gracilis to carbofuran.

190 EC50 and NEC of carbofuran toward freshwater and marine phytoplankton growth rate are listed in Table 2. Due to the large variability in $S$. capricornutum growth in replicates and strong hormesis, the endpoints were not determined for this species.

EC50 values relative to marine algae were lower than for 195 freshwater algae. These endpoints allowed us to rank these three species in ascending order in terms of their sensitivity
TABLE 2

Carbofuran standards regarding the marine phytoplanktons C. gracilis and P. tricornutum and the freshwater species $C$. vulgaris

\begin{tabular}{lccc}
\hline & C. gracilis & P. tricornutum & C. vulgaris \\
\hline $\mathrm{NEC}, \mathrm{mg} / \mathrm{L}$ & $3.13 \pm 0.08$ & $1.42 \pm 0.09$ & $1.33 \pm 0.08$ \\
$\mathrm{EC} 50, \mathrm{mg} / \mathrm{L}$ & 5.11 & 7.13 & 9.96 \\
$(\mathrm{CI})$ & $(4.80-5.38)$ & $(6.72-7.46)$ & $(9.14-10.73)$ \\
\hline
\end{tabular}

NEC and EC50 values given at the 95\% confidence level. CI: confidence interval estimated by a bootstrap simulation. S. capricornutum has been eliminated due to its stated variability.

toward carbofuran: $C$. vulgaris $<P$. tricornutum $<$ C. gracilis. However, the NEC values estimated by DEBtox give a reverse ranking.

\section{Effect of Isoproturon}

At $13 \mu \mathrm{g} / \mathrm{L}$ this herbicide stimulated the growth of freshwater phytoplankton species by about 5\%; on the other hand,
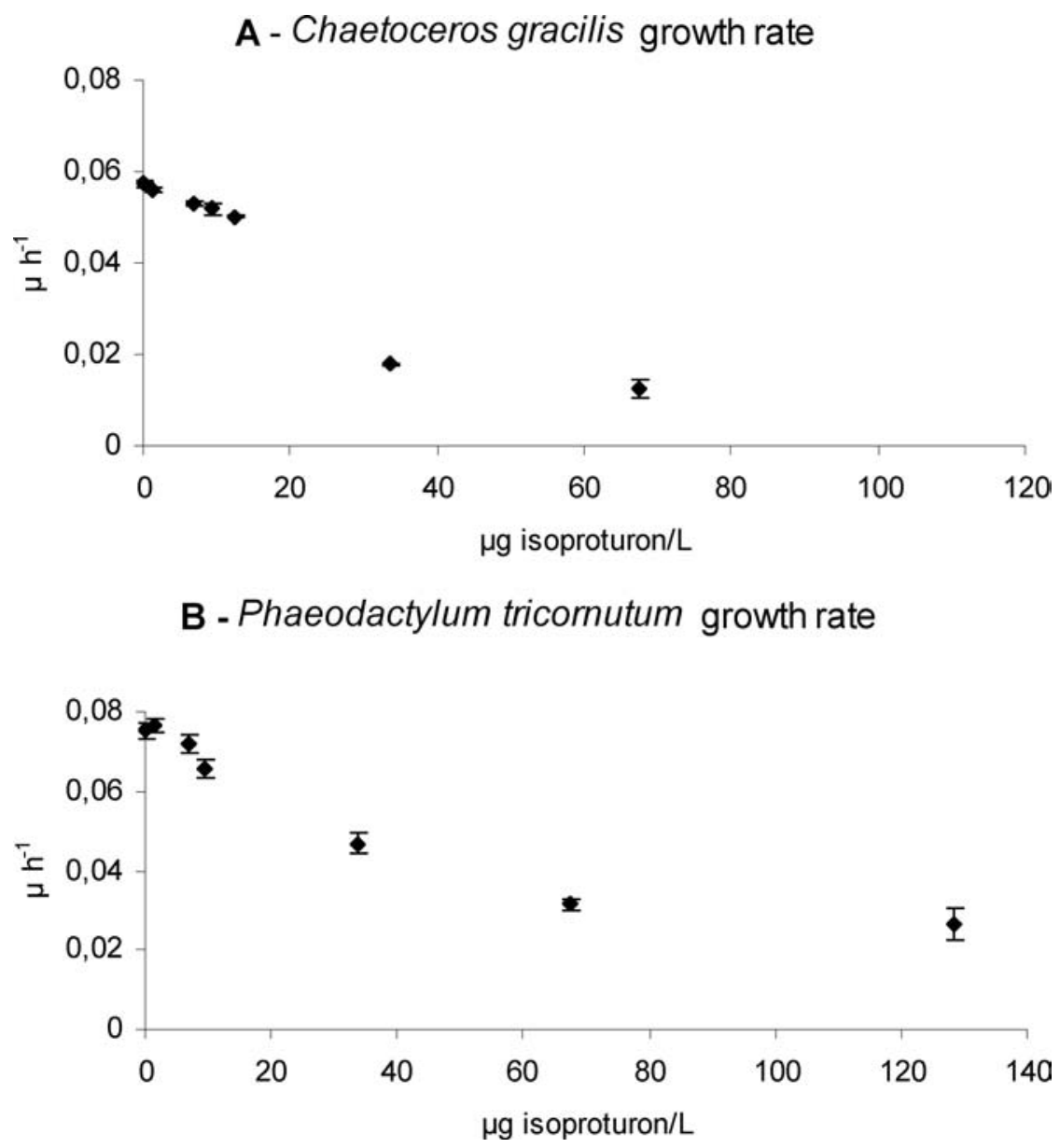

FIG. 4. Marine algae growth rate versus different doses of isoproturon. A: C. gracilis; B: P. tricornutum. $\mathrm{N}=3$, bars: standard deviation for $95 \%$ confidence level. 
TABLE 3

Isoproturon standards towards the marine phytoplankton P. tricornutum and C. gracilis, and the freshwater phytoplankton, S. capricornutum and C. vulgaris

\begin{tabular}{lcccc}
\hline & C. gracilis & P. tricornutum & C. vulgaris & S. capricornutum \\
\hline $\mathrm{NEC}, \mu \mathrm{g} / \mathrm{L}$ & $11.90 \pm 0.38$ & $16.28 \pm 4.73$ & $38.26 \pm 5.87$ & $38.89 \pm 8.47$ \\
$\mathrm{EC} 50, \mu \mathrm{g} / \mathrm{L}$ & 26.84 & 53.10 & 117.93 & 141.89 \\
$(\mathrm{CI})$ & $(24.32-29.99)$ & $(45.93-60.26)$ & $(105.47-139.38)$ & $(108.98-165.91)$ \\
\hline
\end{tabular}

NEC and EC50 values given at the $95 \%$ confidence level. CI: confidence interval estimated by a bootstrap simulation.

isoproturon at high concentrations inhibited the culture growth (Fig. 3). The main difference was the degree of growth rate inhibition calculated for the same level of concentration: at $89 \mu \mathrm{g} / \mathrm{L}$, isoproturon caused $22 \%$ inhibition on S. capricornutum and $35 \%$ on C. vulgaris. The concentration of $475 \mu \mathrm{g} / \mathrm{L}$ was tested only on $S$. capricornutum and resulted in total inhibition (not represented in Fig. 3B).

210 Marine species were also inhibited in growth, but with lower isoproturon concentrations than the ones mentioned above: A dose of $33.7 \mu \mathrm{g} / \mathrm{L}$ reduced the growth rate by 40 and $70 \%$ in P. tricornutum and C. gracilis, respectively (Fig. 4).

Table 3 gives ecotoxicological standards for isoproturon;

215 it shows that NEC values for both marine algae are not significatively different. The same observation is also valid for freshwater algae, but the concentrations are twofold higher than for marine species. The comparison of EC50 values allows the following ranking in algal sensitivity level: $S$. capricornutum $\cong$ C. vulgaris $\ll P$. tricornutum $<$ C. gracilis.

\section{CONCLUSION}

Compared to the insecticide carbofuran, the herbicide isoproturon displayed higher toxicity toward phytoplankton; this expected result is attributable to their different modes of 225 action as highlighted by their respective EC50, which showed a huge difference in order of magnitude (Robert 1998; Robert and Hutson 1999).

Instead of NOEC (no-observed effect concentration), which is dependent on the test design, NEC obtained with the DEBtox

230 model is estimated with a confidence interval. The application of NEC in threshold determination is of great interest for environmental conservation. P. tricornutum and C. vulgaris showed comparable sensitivities to carbofuran $(\mathrm{NEC}=1.2$ to $1.5 \mathrm{mg} / \mathrm{L}$ ), unlike those displayed against isoproturon: This 235 toxicant was twice more potent with respect to marine species than to freshwater ones (confidence interval for NEC $=11$ to $21 \mu \mathrm{g} / \mathrm{L}$ and 30 to $47 \mu \mathrm{g} / \mathrm{L}$, respectively).

Marine species were more sensitive than freshwater species to both toxicants in agreement with literature data about aro-

240 matic hydrocarbons (Kusk 1981) and atrazine. The differential toxicity of atrazine was studied in three marine species by Weiner et al. (2004), and the respective EC50 varied within the range 44 to $91 \mu \mathrm{g} / \mathrm{L}$ after 4 day's exposure. In six out of eight freshwater species studied by Tang et al. (1997), the EC50 values were within the range of 171 to $537 \mu \mathrm{g} / \mathrm{L}$ after 7 days' 245 exposure.

Whatever the pesticide used in toxicity assessment, our EC50 results confirm the higher toxicity of pesticides toward marine phytoplankton than toward freshwater phytoplankton. These results provide further evidence that it is worth developing 250 standard tests for the marine environment as planned in the Technical Guidance Document, instead of relying on freshwater extrapolation, to address the Water Framework Directive (ECB 2001; Babut et al. 2003). Improvements in marine environment conservation should be based on toxicity assessment, focusing 255 on the selection of a particular pesticide-sensitive species like C. gracilis.

As mentioned in DeLorenzo et al. (2001), there is a severe lack of marine and estuarine ecotoxicology data. Published data concern mainly CE50 of pesticide in freshwater species: 260 Gangolli et al. (1999) obtained $204 \mathrm{mg} / \mathrm{L}$ for carbofuran in Chlorella pyrenoidosa growth after 96 hours of exposure, and Rioboo et al. (2002) obtained $41 \mu \mathrm{g} / \mathrm{L}(0.199 \mu \mathrm{M})$ for isoproturon in Chlorella vulgaris. Using fluorescence endpoints in natural freshwater communities, Dorigo et al. (2004) 265 calculated EC50 14.44 to $1396 \mu \mathrm{g} / \mathrm{L}$ isoproturon, depending on the composition of the algal species assemblage and the season. Seguin et al. (2001) showed the higher sensitivity of freshwater natural complex communities to the toxic effect of pesticides compared to monospecific test responses. It is 270 difficult to compare results due to the many factors influencing the response: methods applied by the authors in algal culture (sometimes use of organic solvent), target species, growth duration, pesticide hydrosolubility, and concentration estimation (nominal or effective). Controlling high-nutrient concentrations, 275 optimal enlighting, and temperature in the standard methods ensures a rapid and reproductive growth, but this does not represent realistic conditions for microalgae growth (Meyer Q1 et al. 1998). Response to the toxicant also varies according to the strain within the same species (Behra et al. 1999), the 280 genus and the communities composition (Seguin et al. 2001), and the exposure duration (Gustavson et al. 2003; Pennington and Scott 2001). Our results demonstrate that the environment from where the algae originate, either marine or freshwater, 
actually constitutes an additional factor to be taken into account when testing the toxic potency of pesticides.

\section{REFERENCES}

Association Française de Normalisation. 1993. Qualité de l'eau-Essai d'inhibition de la croissance des algues d'eau douceavec Scenedesmus subspicatus et Selenastrum capricornutum. NF EN ISO 28692, T90-304, 6p. Paris: AFNOR.

Association Française de Normalisation. 1998. Qualité de l'eau-Essai d'inhibition de la croissance des algues marines avec Skeletonema costatum et Phaeodactylum tricornutum. NF EN ISO 10253, T90-311, 8p. Paris: AFNOR.

Babut, M., Bonnet, C., Bray, M., Flammarion, P., Garric, J., and Golaszewski, G. 2003. Developing environmental quality standards for various pesticides and priority pollutants for French freshwaters. J. Environ. Manage. 69:139-147.

Behra, R., Genoni, G. P., and Joseph, A. L. 1999. Effect of atrazine on growth, photosynthesis, and between-strain variability in Scenedesmus subspicatus (Chlorophyceae). Arch. Environ. Contam. Toxicol. 37:36-41.

Bérard, A., and Pelte, T. 1996. Effets de l'atrazine sur l'évolution des peuplements phytoplanctoniques lacustres-Etude en enceintes expérimentales in situ. Ecologie. 27:195-201.

305 DeLorenzo, M. E., Scott, G. I., and Ross, P. E. 2001. Toxicity of pesticides to aquatic microorganisms: a review. Environ. Toxicol. Chem. 20:84-98.

Dorigo, U., Bourrain, X., Bérard, A., and Leboulanger, C. 2004. Seasonal changes in the sensitivity of river microalgae to atrazine and isoproturon along a contamination gradient. Sci. Total. Environ. 318:101-114.

310 Durand, G., Chiron, S., Bouvot, V., Barcelo, D., Tavares, T., and Klockow, D. 1992. Use of extraction disks for trace enrichment of various pesticides from river and sea water samples. Int. J. Environ. Anal. Chem. 49:31-42.

European Chemicals Bureau. 2001. Draft revised technical guidance document on environmental effects assessment, p. 163. ECB.

315 El Jay, A., Ducruet, J.-M., Duval, J.-C., and Pelletier, J.-P. 1997. A high-sensitivity chlorophyll fluorescence assay for monitoring herbicide inhibition of photosystem II in the chlorophyte Selenastrum capricornutum: comparison with effect on cell growth. Arch. fuer. Hydrobiol. 140:273-286.

European Chemicals Bureau, 2006. Technical Guidance Document on Risk assessment (edition 2) Part II. Chapter 3-4, Environmental Risk assessmentmarine, pp. 134-171. European Commission Joint Research Center EUR $20418 \mathrm{EN} / 2$.

Gangolli, S., Anderson, D., Chadwick, J., Ebdon, L., Gammon, D., King, L., McClellan, R., Rowland, I., Solbe, J., Sugimura, T., and Van Bladeren, P. 1999. The Dictionary of Substances and Their Effects, Vol. 4, The Royal Society of Chemistry, Cambridge, 2nd ed., pp. 877879.

Gustavson, K., Mohlenberg, F., and Schlüter, L. 2003. Effects of exposure duration of herbicides on natural stream periphyton communities and recovery. Arch. Environ. Toxicol. 45:48-58.

His, E., and Seaman, M. N. L. 1993. Effect of twelve pesticides on larvae of oysters (Crassostrea gigas) and on two species of unicellular marine algae (Isochrysis galbana and Chaetoceros calcitrans). ICES C.M./E:22. Marine Environmental Quality Commitee, 8 pp.
IFEN, 2001. Les pesticides dans les eaux-Bilan des données 1998 et 1999, 335 IFEN, Orléans, $n^{\circ} 34,117 \mathrm{p}$.

Kooijman, S. A. L. M., Hansveit, A. O., and Nyholm, N. 1996. No-effect concentrations in algal growth, inhibition tests. Wat. Res 30:1625-1632.

Kusk, K. O. 1981. Comparison of the effects of aromatic hydrocarbons on a laboratory alga and natural phytoplankton. Botanica. Marina. 24:611-613. 340

Mayer, P., Frickmann, J., Christensen, E. R., and Nyholm, N. 1998. Influence of growth conditions on the results obtained in algal toxicity tests. Environ. Toxicol. Chem. 17:1091-1098.

Molina, C., Durand, G., Barcelo, D., and Van-der-Greddf, J. 1995. Trace determination of herbicides in estuarine waters by liquid chromatography-high- 345 flow pneumatically assisted electrospray mass spectrometry. J. Chromatog. A. 712:113-122.

Pennington, P. L., and Scott, G. I. 2001. Toxicity of atrazine to the estuarine phytoplankter Pavlova sp. (Prymnesiophyceae): increased sensitivity after long term low-level population exposure. Environ. Tox. Chem. 20:22372242.

Petersen, S., and Gustavson, K. 2000. Direct toxic effects of TBT on natural enclosed phytoplankton at ambient TBT concentrations of coastal waters. Ecotoxicology. 9:273-285.

Organization for Economic Cooperation and Development. 1994. Guidance document for aquatic effects assessment (draft), OECD Environmental Monographs, $\mathrm{N}^{\circ}$ 92, Paris, 113.

Oudin, L.C., and Maupas, D. 1999. Système d'évaluation de la qualité de l'eau des cours d'eau. Rapport de présentation SEQ-Eau (version 1), Agences de l'eau Orléans, p. 59.

Rioboo, C., Gonzàlez, C., Herrero, C., and Cid, A. 2002. Physiological response of freshwater microalga (Chlorella vulgaris) to triazine and phenylurea herbicides. Aquat. Toxicol. 59:225-235.

Robert, T., and Hutson, D. 1999. Metabolic Pathways of Agrochemicals. Part two: Insecticides and Fungicides. The Royal Society of Chemistry. Editorsin-chief Roberts, T. and Hutson, D., pp. 25-33

Robert, T. 1998. Metabolic Pathways of Agrochemicals. Part one: Herbicides and Plant Growth Regulators. The Royal Society of Chemistry. Editor-inchief Roberts T., pp. 735-739

Seguin, F., Leboulanger, C., Rimet, F., Druart, J. C., and Bérard, A. 2001. Effects of atrazine and nicosulfuron on phytoplankton in systems of increasing complexity. Arch. Environ. Contam. Toxicol. 40:198-208.

Stebbing, A. R. D. 1982. Hormesis-the stimulation of growth by low levels of inhibitors. Sci. Total. Environ. 22:213-234.

Tang, J. X., Hoagland, K. D., and Siegfried, B. D. 1997. Differential toxicity 375 of atrazine to selectd freshwater algae. Bull. Environ. Contam. Toxicol. 59:631-637.

Varela, M., Prego, R., Pazos, Y., and Moronos, A. 2005. Influence of upwelling and river runoff interaction on phytoplankton assemblages in a Middle Galician Ria and Comparison with northern and southern rias (NW Iberian 380 Peninsula). Estuarine. Coastal. Shelf. Sci. 64:721-737.

Vindimian, E., Robaut, C., and Fillion, G. 1983. A method for cooperative and non comparative binding studies using non regression analysis on a microcomputer. J. Appl. Biochem. 5:261-268.

Weiner, J. A., DeLorenzo, M. E., and Fulton, M. H. 2004. Relationship between 385 uptake capacity and differential toxicity of the herbicide atrazine in selected microalgal species. Aquat. Toxicol. 68:121-128. 